Instituto de Estudos Sócio-Ambientais

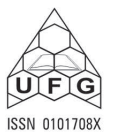

BOLETIM GOIANO DE GEOGRAFIA

v. 26, n. 1, jan./jun. 2006

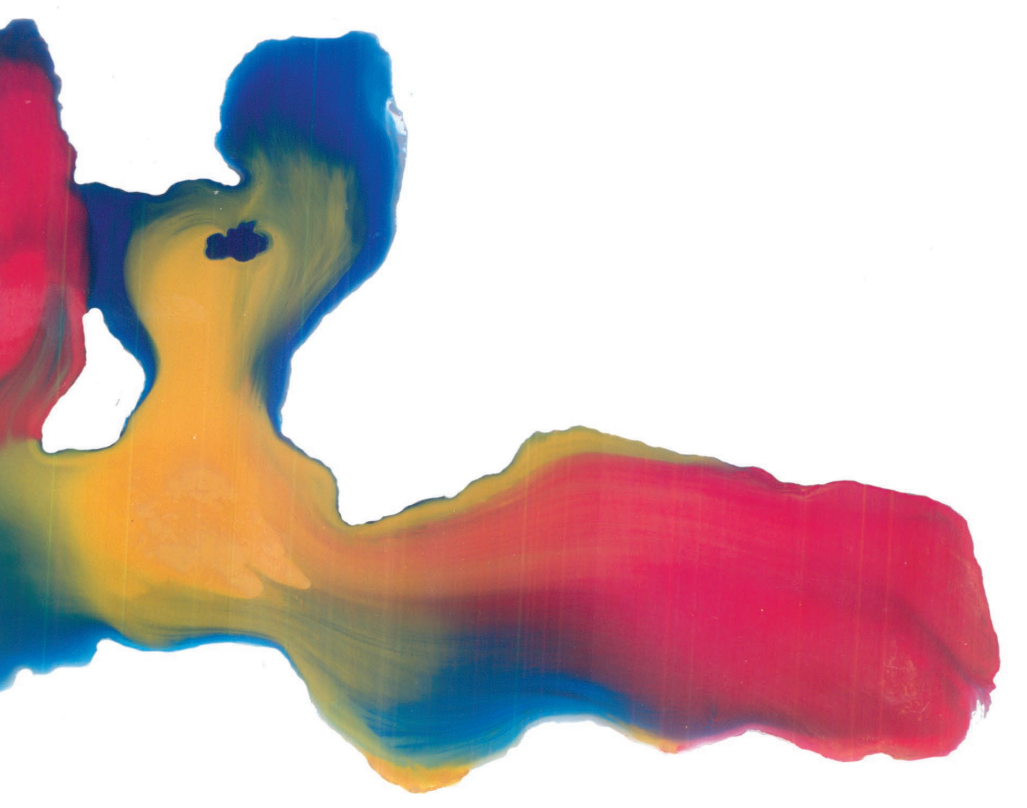

$\infty$
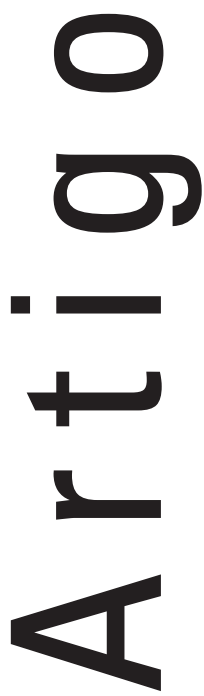


\title{
UMA CONTRIBUIÇÃO DO SENSORIAMENTO REMOTO PARA DETECÇÃO DE ÁREAS DEGRADADAS NA CAATINGA BRASILEIRA
}

\author{
UNA CONTRIBUCIÓN DE DETECCIÓN REMOTA PARA EL DESCUBRIMIENTO \\ DE ÁREAS DEGRADADO EN LA SABANA BRASILEÑA
}

\author{
Admilson P. Pacheco - UFPE \\ admilpp@ufpe.br \\ Neison Cabral Ferreira Freire - UFPE \\ neisonfreire@ibest.com.br \\ Utaiguara da Nóbrega Borges - UFPE \\ utaiguara@yahoo.com.br
}

Resumo

Em países pobres, o consumo dos recursos naturais não isenta a população do ciclo vicioso da pobreza e da degradação ambiental. No Brasil, o semi-árido é uma das regiões mais afetadas pelo problema, ocasionando processos desertificatórios crescentes com graves conseqüências sócio-ambientais. Com o objetivo de contribuir com a inversão desse quadro, o presente artigo trata das técnicas de Sensoriamento Remoto, mais especificamente o de nível orbital, como uma contribuição para detecção de áreas degradadas na Caatinga Brasileira.

Palavras-chave: desertificação, sensoriamento remoto, caatinga, semi-árido, degradação ambiental.

\begin{abstract}
In poor countries, the consumption of the natural resources no exempt the population of the vicious cycle of the poverty and of the environmental degradation. In Brazil, the semi-arid is one of the most affected areas for the problem, causing processes growing desertification with serious partner-environmental consequences. With the objective of contributing with the inversion of that picture, the present article treats of the techniques of Remote Sensing, more specifically the one of orbital level, as a contribution for detection of areas degraded in the Brazilian Savanna.
\end{abstract}

Key-words: remote sensing, savanna, half-arid, environmental degradation, desertification. 


\section{Introdução}

\section{Princípios do sensoriamento remoto}

O Sensoriamento Remoto trata da aquisição de dados de um objeto ou cena por um sensor que está distante dos alvos (Colwell, 1983). Fotografias aéreas, imagens de satélite e de radar são exemplos de produtos gerados a partir de dispositivos remotamente sensoriados.

Os sensores utilizados em Sensoriamento Remoto basicamente registram a radiação eletromagnética - uma energia transmitida pelo espaço na forma de ondas elétricas e magnéticas (STAR \& EsTES, 1990). Jensen (1999) afirma que os sensores remotos são feitos por detectores que registram comprimentos de onda específicos no espectro eletromagnético (Figura 1). Este espectro abrange o intervalo de radiação eletromagnética que vai desde as ondas cósmicas, até as ondas de rádio.

Figura 1: Espectro eletromagnético

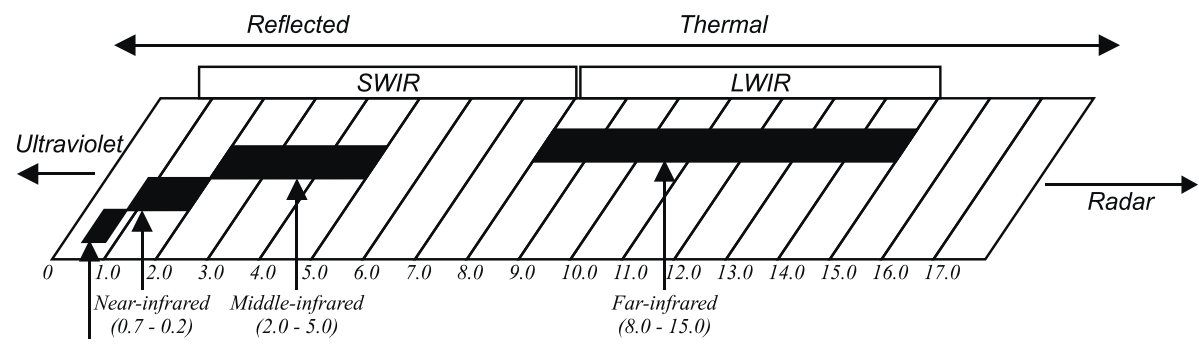

Visible $(0.4-0.7)$

Blue $(0.4-0.5)$

Green $(0.5-0.6)$

$\operatorname{Red}(0.6-0.7)$

micrometers $\mu$ m (one millionth of a meter)

Fonte: Erdas (1999).

A diferença no comprimento de onda da energia eletromagnética está diretamente relacionada com a quantidade de energia que a onda carrega, diferenciando, assim, as formas de radiação (refletida e emitida - ou termal), podendo-se afirmar que quanto menor o comprimento de onda da radiação, maior é a sua energia (Novo, 1989).

Segundo Moreira (2003), "para o sensoriamento remoto, a energia solar é a base de todos os princípios em que se fundamenta essa tecnologia", pois mesmo os sensores ativos, como os radares, necessitam da radiação solar para manter suas reservas de energia, necessárias ao funcionamento dos 
equipamentos e permanência em órbita da Terra. “Quando o Sol é utilizado como fonte de energia, em Sensoriamento Remoto, o que se mede é a energia refletida pelos diversos objetos da superfície terrestre” (INPE, 2001).

O processo de fusão nuclear que ocorre na zona radioativa do Sol produz várias radiações eletromagnéticas, com diferentes comprimentos de onda contidos no intervalo entre 0,3 a $4,0 \mu \mathrm{m}$, sendo por esta razão denominadas de ondas curtas (Figura 2). Por outro lado, as "radiações produzidas pela emissão de energia da Terra são chamadas de ondas longas. Alem disso, o Sol emite radiações eletromagnéticas com diferentes intensidades radiantes, e as de maiores intensidades localizam-se na região do visível e do infravermelho próximo" (MOREIRA, 2003), onde a maioria das atividades em Sensoriamento Remoto é desenvolvida. Outras regiões, ou faixas compõem o espectro eletromagnético, de acordo com suas características físicas de detecção de energia (JENSEN, 1999).

Figura 2: Espectro da emissão do Sol e da Terra e absorção pelos elementos da atmosfera

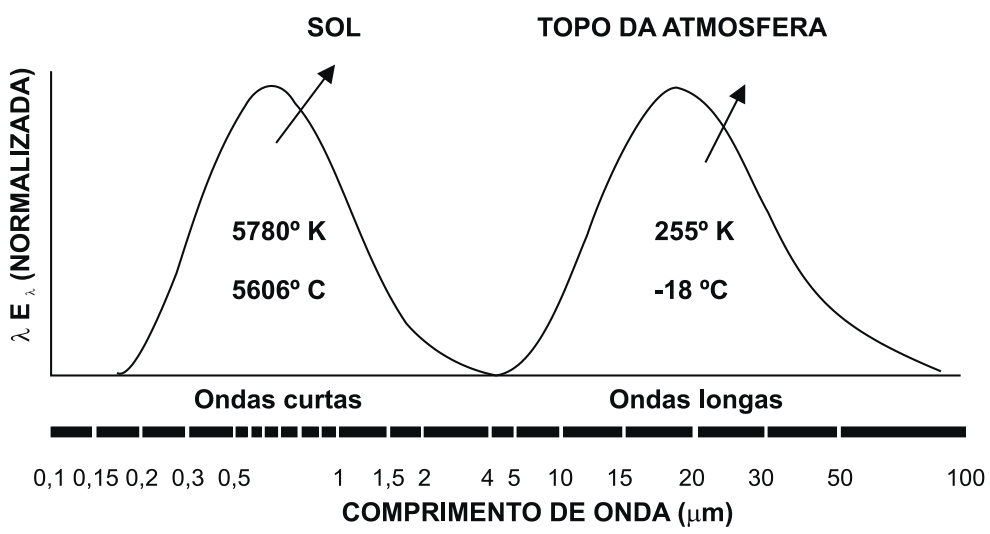

Fonte: Moreira (2003).

Os sensores são equipamentos formados por sistemas fotográficos ou óptico-eletrônicos utilizados para a coleta da energia eletromagnética refletida ou emitida pelos alvos terrestres, convertendo-a em sinal passível de ser registrado para uma posterior extração de informações do ambiente (Novo, 1989). O INPE (2001) afirma que os elementos básicos da fase de aquisição de dados pelos sensores são: "energia radiante, fonte de radiação, objeto (alvo), trajetória e sensor (sistema de imageamento óptico e detector)”. 
O ciclo total do processo envolve simultaneamente a emissão, absorção, reflexão e transmissão da energia eletromagnética. Neste processo, a atmosfera interage com a radiação solar, interferindo na energia final registrada pelo sensor (Florenzano, 2002). De fato, segundo Moreira (2003), para o Sensoriamento Remoto, "o estudo da atmosfera terrestre como um todo é fundamental, porque constitui um meio natural que interfere tanto na radiação incidente (irradiância), quanto na parte da radiação que é refletida ou emitida (radiância) pelos alvos da superfície que, eventualmente, será coletada pelos sistemas sensores”, manifestando-se na trajetória (fenômenos de refração e difração), na velocidade e absorção em determinadas faixas do espectro eletromagnético. Ao atravessar a atmosfera terrestre e chegar à superfície terrestre, a radiação solar é fortemente atenuada pela "reflexão, espalhamento e absorção pelos constituintes atmosféricos, por partículas dispersas e nuvens" (Figura 3).

Figura 3: Causas das atenuações da energia solar ao atravessar a atmosfera terrestre.

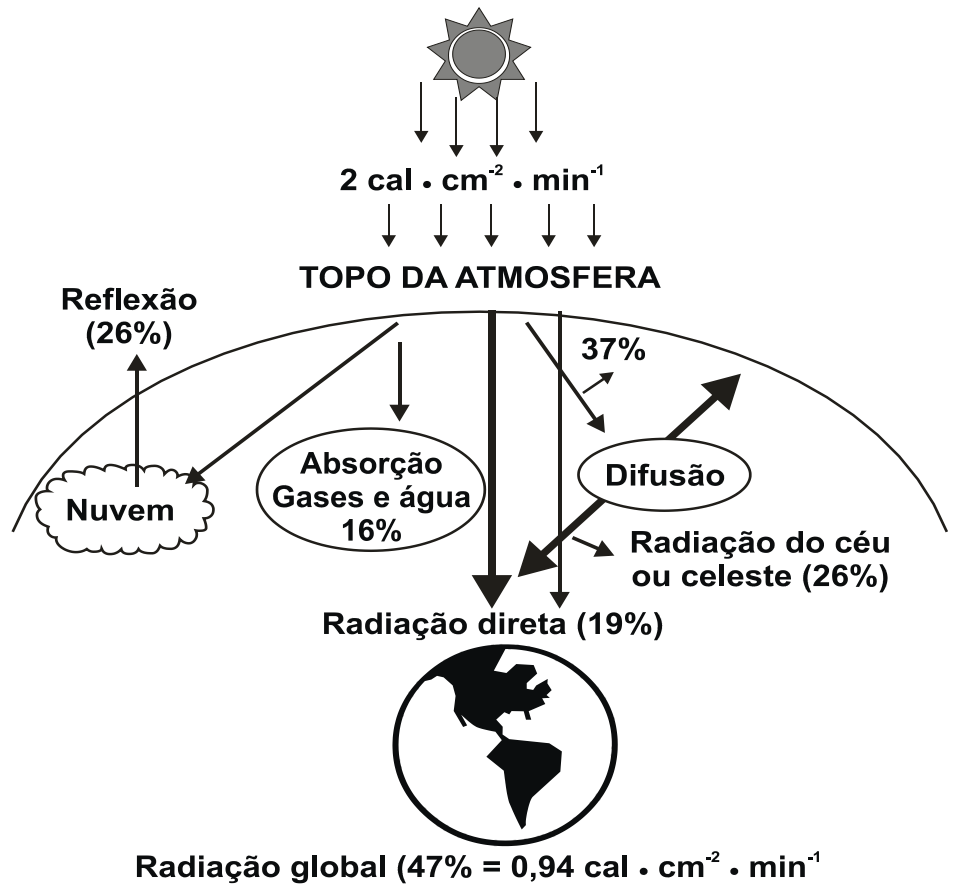

Fonte: Moreira (2003). 
Devido às diferentes propriedades bio-físico-químicas, todos os alvos da superfície terrestre (rochas, corpos d'água, vegetação, etc.) absorvem uma porção específica do espectro eletromagnético, permitindo uma assinatura identificável de radiação eletromagnética. Assim, conhecendo qual comprimento de onda é absorvido por um determinado alvo e também qual a intensidade de sua reflectância, torna-se possível analisar uma imagem de Sensoriamento Remoto e obterem-se interpretações acuradas de uma determinada cena orbital (SUITS, 1983; STAR \& EsTES, 1990). Esse comportamento espectral dos alvos é chamado de "assinatura espectral”, ou seja, um valor específico de reflectância dentro do espectro eletromagnético (Figura 4), permitindo ao Sensoriamento Remoto distinguir os diversos materiais ou alvos entre si.

Figura 4: Curvas espectrais de diferentes alvos

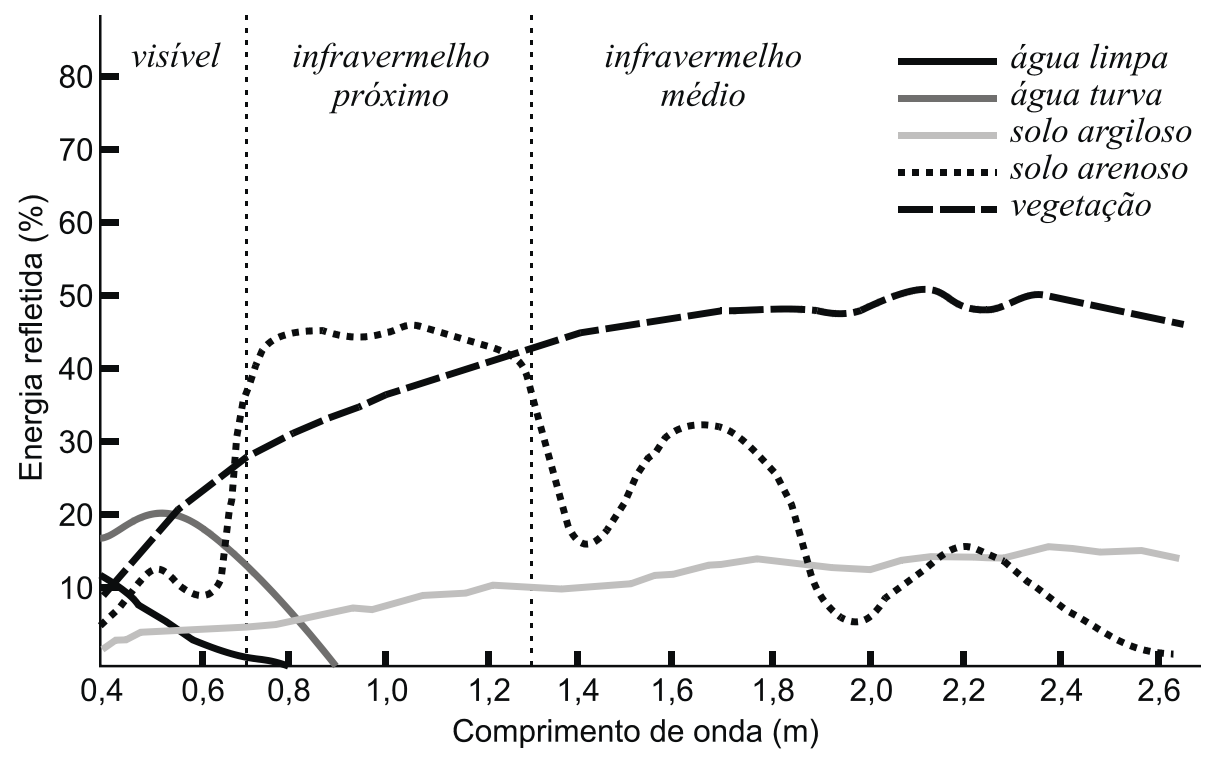

Fonte: Florenzano (2002).

Segundo Novo (1989), os sensores podem ser classificados em passivos ou ativos. Os sensores passivos detectam a radiação solar refletida ou a radiação emitida pelos objetos da superfície terrestre, dependendo, portanto, "de uma fonte de radiação externa para que possam operar", como, por exemplo, os sistemas fotográficos. Por outro lado, os sensores ativos produzem sua própria radiação, como os radares, por exemplo. 
Outra classificação diz respeito ao tipo de produto gerado pelos sensores orbitais, dividindo-se em:

a) Não-imageadores: não fornecem uma imagem da superfície sensoriada; como exemplo, os radiômetros (com saída em dígitos ou gráficos) e os espectro-radiômetros (utilizados para assinatura espectral dos alvos);

b) Imageadores: fornecem informações sobre a variação espacial da resposta espectral da superfície observada (cena), sendo possível gerar imagens desta superfície. Subdividem-se em:

b1) sistema de quadros (frame): adquirem a imagem da cena em sua totalidade num mesmo instante, como, por exemplo, as imagens RBV (Return Beam Vidicon), coletadas à bordo dos satélites LandSAT 1, 2 e 3, já desativados;

\section{b2) sistema de varredura:}

- Mecânica: utiliza um sistema óptico grande-angular, onde a cena é captada através de um arranjo linear de detectores ou elemento de resolução (pixel), à medida que a plataforma se locomove ao longo da órbita, sendo em seguida convertido para um sinal digital passível de transmissão; são exemplos os sensores MSS (LandSAT 1, 2 e 3) e TM (LandSAT 4, 5 e 7).

- Eletrônica: tem o mesmo princípio de funcionamento do anterior, porém utilizando um sistema eletro-óptico-eletrônico, onde os dados são originados digitalmente; são exemplos os sensores HRV (SPOT 4 e 5);

Muitos são os sistemas orbitais em atividade atualmente. Nas aplicações civis, destacam-se os sistemas de observação da Terra, com multi-bandas e multi-sensores, tais como o LandSAT 5 TM e 7 ETM+, o SPOT 4 e 5, o Ikonos 2, o QuickBird, o Aster e o CBERS-2.

De uma maneira em geral, esses sistemas apresentam as seguintes premissas:

- Órbita (Figura 5):

- Circular, para garantir imagens de diferentes regiões da Terra com mesma escala e resolução;

- Sol-síncrona: síncrona com o Sol (heliossíncrono), garantindo condições constantes de iluminação da superfície terrestre; (altitude de 200 a $1.000 \mathrm{~km}$ );

- Polar: direção circular norte - sul que permite observar toda a superfície da Terra; inclinação de $90^{\circ}$; altitude de 200 a 1.000 km; 
- Geoestacionária: inclinação de $0^{\circ}$, constituindo-se de uma única órbita acima do Equador, mantendo, dessa forma, a mesma posição em relação a um ponto fixo na superfície e obtendo sempre imagens da mesma face da Terra; altitude de $35.000 \mathrm{~km}$;

- Imageamento cíclico da superfície, garantindo observações periódicas e repetitivas dos mesmos lugares;

- Horário de passagem do satélite atendendo às solicitações de diferentes áreas de aplicação.

Figura 5: Órbitas de satélites artificiais

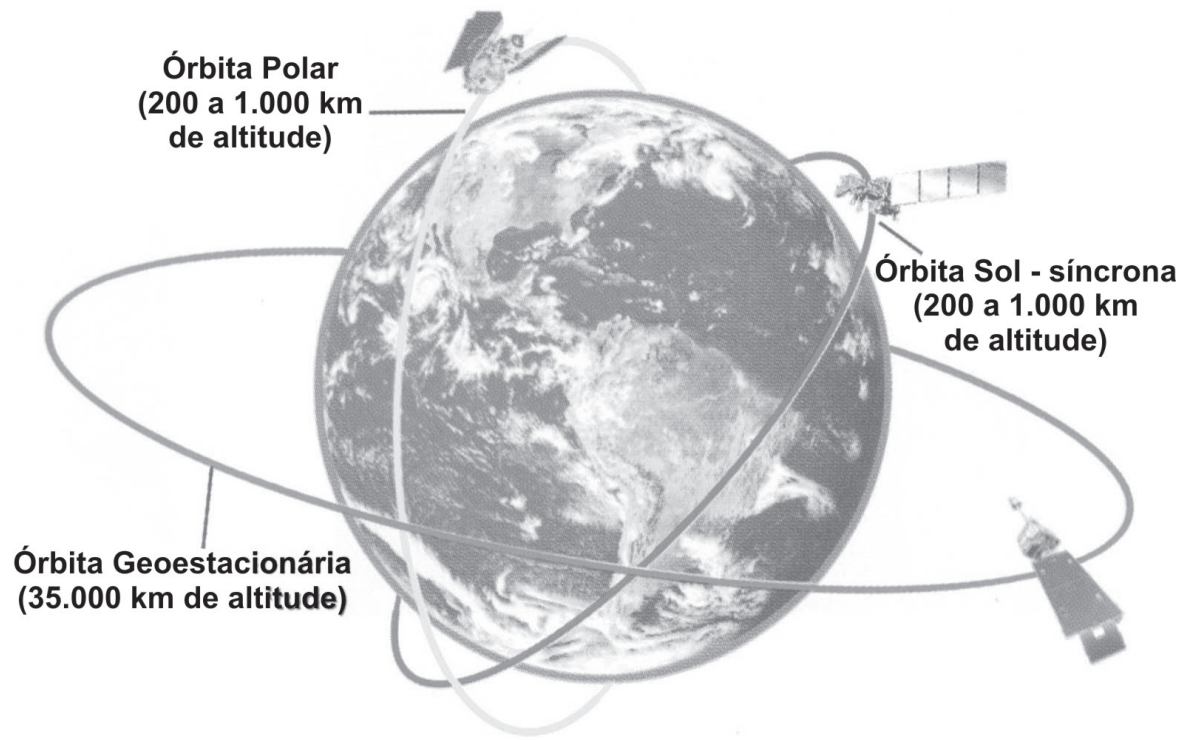

Fonte: Florenzano (2002).

Desenvolvida pela NASA, a série de sistemas LandSAT (Quadro 1) atualmente está na versão 7, operando com o sistema sensor ETM+ (Enhanced Thematic Mapper Plus), onde, além de contar com as bandas disponíveis no LandSAT 5 TM (avançado sistema sensor de varredura multiespectral, operando em 7 faixas espectrais), conta com uma banda pancromática de resolução espacial igual a 15 m e um canal termal com resolução espacial de $60 \mathrm{~m}$. Um espelho de varredura capta a energia proveniente da cena, oscilando perpendicularmente à direção de deslocamento do satélite em sentido leste-oeste. Depois de corrigido, o sinal detectado pelo sistema LandSAT é 
amplificado e convertido em sinal digital, sendo transmitido via telemetria, no Brasil desde 1973, para a Estação de Recepção do INPE, em Cuiabá/MT (Figura 6).

Uma vez armazenadas, as imagens são enviadas à Divisão de Geração de Imagens - DGI - no Centro Espacial de Cachoeira Paulista/SP (Figura 7) e ficam disponíveis para o público em geral, através de diversos produtos (cópias em papel em diferentes escalas e formatos, fitas digitais e CD-ROM) e níveis de correção (Quadro 2).

Quadro 1: Características principais dos sistemas sensores LandSAT 5 e 7

\begin{tabular}{|l|l|}
\hline \multicolumn{1}{|c|}{ Padrão } & \multicolumn{1}{c|}{ Característica } \\
\hline Órbita & Circular - 98,2 - heliossíncrona \\
\hline Período & $99 \mathrm{~min}$ \\
\hline Altitude & $705 \mathrm{~km}$ \\
\hline Cruzamento & $09: 45 \mathrm{~h}$ \\
\hline Ciclo & $16 \mathrm{dias}$ \\
\hline Órbita adjacente & $172 \mathrm{~km}$ \\
\hline Velocidade & $7,7 \mathrm{~km} / \mathrm{s}$ \\
\hline Tempo de obtenção de uma cena & $24 \mathrm{~s}$ \\
\hline
\end{tabular}

Fonte: INPE (2001).

Quadro 2: Níveis de Correção disponibilizados pelo INPE para imagens LandSAT

\begin{tabular}{|l|l|}
\hline \multicolumn{1}{|c|}{ Nível } & \multicolumn{1}{c|}{ Correção } \\
\hline Nível 0R & $\begin{array}{l}\text { Dados brutos com as bandas espectrais } \\
\text { alinhadas espacialmente }\end{array}$ \\
\hline Nível 1R & $\begin{array}{l}\text { Imagem com correção radiometrica sem } \\
\text { associação com sistema de projeção }\end{array}$ \\
\hline Nível 1G & $\begin{array}{l}\text { Imagem com correções radiometrica e } \\
\text { geométrica associada a um sistema de projeção }\end{array}$ \\
\hline
\end{tabular}

Fonte: INPE (2003).

Um mapa base, na escala de 1:10.000.000, foi elaborado pelo INPE/

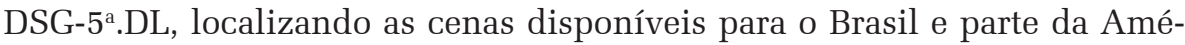
rica do Sul e identificando-as por órbitas (path) e pontos (row). Cada cena cobre uma área de $185 \mathrm{~km}$ x $185 \mathrm{~km}$, com bandas espectrais cuja resolução espacial varia entre 15 e 120 m e aplicações específicas (Quadro 3). 
Quadro 3: Características e aplicações das bandas espectrais do LandSAT 5.

\begin{tabular}{|c|c|c|}
\hline Banda & $\begin{array}{c}\text { Intervalo } \\
\text { espectral }(\mu \mathrm{m})\end{array}$ & $\begin{array}{c}\text { Principais características e aplicaçóes das bandas } \\
\text { TM do satélite LANDSAT-5 }\end{array}$ \\
\hline 1 & $(0,45-0,52)$ & $\begin{array}{l}\text { Apresenta grande penetração em corpos de água, com elevada } \\
\text { transparência, permitindo estudos batimétricos. Sofre absorção pela } \\
\text { clorofila e pigmentos fotossintéticos auxiliares (carotenóides). Apresenta } \\
\text { sensibilidade a plumas de fumaça oriundas de queimadas ou atividade } \\
\text { industrial. Pode apresentar atenuação pela atmosfera. }\end{array}$ \\
\hline 2 & $(0,52-0,60)$ & $\begin{array}{l}\text { Apresenta grande sensibilidade à presença de sedimentos em suspensão, } \\
\text { possibilitando sua análise em termos de quantidade e qualidade. Boa } \\
\text { penetração em corpos de água. }\end{array}$ \\
\hline 3 & $(0,63-0,69)$ & $\begin{array}{l}\text { A vegetação verde, densa e uniforme, apresenta grande absorção, } \\
\text { ficando escura, permitindo bom contraste entre as áreas ocupadas } \\
\text { com vegetação (ex.: solo exposto, estradas e áreas urbanas). Apresenta } \\
\text { bom contraste entre diferentes tipos de cobertura vegetal (ex.: campo, } \\
\text { cerrado e floresta). Permite análise da vanação litológica em regiões com } \\
\text { pouca cobertura vegetal. Permite o mapeamento da drenagem através da } \\
\text { visualização da mata galeria e entalhe dos cursos dos rios em regiões } \\
\text { com pouca cobertura vegetal. É a banda mais utilizada para delimitar a } \\
\text { mancha urbana, incluindo identificação de novos loteamentos. Permite a } \\
\text { identificação de áreas agrícolas. }\end{array}$ \\
\hline 4 & $(0,76-0,90)$ & $\begin{array}{l}\text { Os corpos de água absorvem muita energia nesta banda e ficam escuros, } \\
\text { permitindo o mapeamento da rede de drenagem e delineamento de } \\
\text { corpos de água. A vegetação verde, densa e uniforme, reflete muita } \\
\text { energia nesta banda, aparecendo bem clara nas imagens. Apresenta } \\
\text { sensibilidade à rugosidade da copa das florestas (dossel florestal). } \\
\text { Apresenta sensibilidade à morfologia do terreno, permitindo a obtenção } \\
\text { de informações sobre Geomorfologia, Solos e Geologia. Serve para análise } \\
\text { e mapeamento de feições geológicas e estruturais. Serve para separar e } \\
\text { mapear áreas ocupadas com pinus e eucalipto. Serve para mapear áreas } \\
\text { ocupadas com vegetação que foram queimadas. Permite a visualização } \\
\text { de áreas ocupadas com macrófitas aquáticas (ex.: aguapé). Permite a } \\
\text { identificação de áreas agrícolas. }\end{array}$ \\
\hline 5 & $(1,55-1,75)$ & $\begin{array}{l}\text { Apresenta sensibilidade ao teor de umidade das plantas, servindo para } \\
\text { observar estresse na vegetação, causado por desequilíbrio hídrico. Esta } \\
\text { banda sofre perturbações em caso de ocorrer excesso de chuva antes da } \\
\text { obtenção da cena pelo satélite. }\end{array}$ \\
\hline 6 & $(10,4-12,5)$ & $\begin{array}{l}\text { Apresenta sensibilidade aos fenômenos relativos aos contrastes térmicos, } \\
\text { servindo para detectar propriedades termais de rochas, solos, vegetação } \\
\text { e água. }\end{array}$ \\
\hline 7 & $(2,08-2,35)$ & $\begin{array}{l}\text { Apresenta sensibilidade à morfologia do terreno, permitindo obter } \\
\text { informações sobre Geomorfologia, Solos e Geologia. Esta banda serve } \\
\text { para identificar minerais com íons hidroxilas. Potencialmente favorável à } \\
\text { discriminação de produtos de alteração hidrotermal. }\end{array}$ \\
\hline
\end{tabular}

Fonte: INPE (2003). 


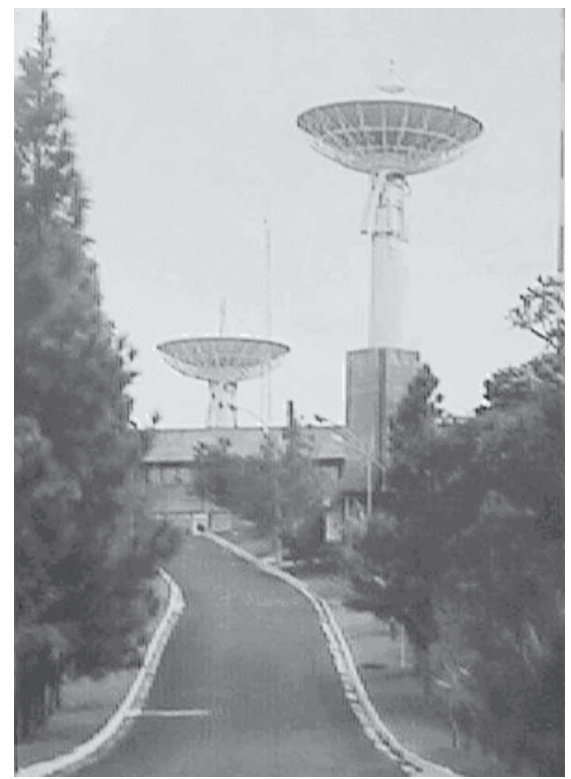

Figura 6: Estação de Recepção LandSAT do INPE em Cuiabá/MT

Fonte: INPE (2003).

Figura 7: Vista aérea do Centro Espacial de Cachoeira Paulista/SP

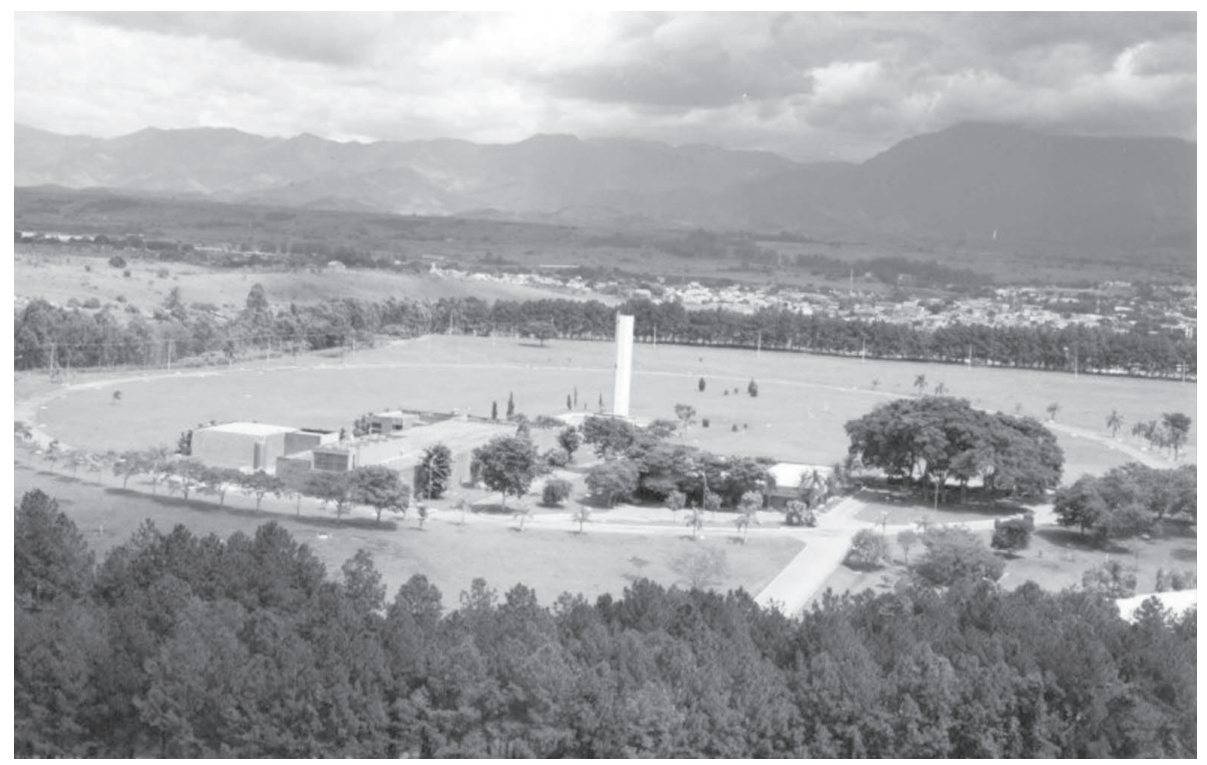

Fonte: INPE (2003). 
Nesta pesquisa, serão utilizadas imagens dos sistemas LandSAT 5 e 7, pelas facilidades de aquisição junto ao INPE, através do Laboratório de Geoprocessamento do Instituto Xingó, além da extensa e consolidada bibliografia científica disponível sobre Sensoriamento Remoto aplicado ao monitoramento ambiental para estes sensores.

\section{Processamento Digital de Imagem e extração de informações em imagens de satélite}

A função primordial do PDI é "facilitar a identificação e a extração de informações contidas nas imagens" (CRÓstA, 1993), removendo barreiras inerentes ao sistema visual humano e objetivando uma posterior interpretação pelo usuário. Para isso são utilizados sistemas computacionais dedicados, onde as imagens brutas são processadas, analisadas e manipuladas, resultando em outras imagens com as informações específicas desejadas, após diversas técnicas de realce e modificação de sua estrutura espectral.

Embora o ser humano seja capaz de reconhecer padrões distintos, o grande volume de dados oriundos das imagens orbitais impossibilita um processamento sem o auxílio da tecnologia digital, que alcançou enorme evolução nas últimas décadas, diminuindo custos ao mesmo tempo em que aumentou a capacidade de armazenamento e processamento dos dados.

As imagens orbitais são diferentes de outras imagens digitais em sua estrutura e resolução. Segundo Crósta (1993), estas imagens têm natureza discreta e são constituídas "por um arranjo de elementos sob a forma de uma malha ou grid", onde cada célula, chamada de pixel (de picture element, em inglês) tem sua localização definida por um sistema de coordenadas $x, y$ (linha e coluna), representando sempre uma área com as mesmas dimensões na superfície terrestre. Associado ao pixel existe um atributo $z$, indicando seu nível de cinza, conhecido por DN (do inglês, digital number), que varia do branco ao preto. Assim, uma imagem pode ser vista como uma matriz composta por milhares de linhas e colunas, onde cada elemento possui um nível de cinza específico, de acordo com a assinatura espectral do alvo imageado.

Qualquer imagem, como uma fotografia em papel, por exemplo, pode ser transformada em imagem digital, utilizando um equipamento scanner. No processo, também é gerada uma matriz com seus elementos em tamanhos 
pré-definidos e seus níveis de cinza proporcionais à tonalidade da imagem original, podendo ser manipulada por sistemas computacionais de processamento de imagem.

O termo "resolução" em PDI diz respeito à medida da habilidade que um determinado sensor possui de distinguir entre respostas que são semelhantes espectralmente ou próximas espacialmente (INPE, 2001). Divide-se em:

a) Resolução espacial: medida em metros, é "definida pela capacidade do sistema sensor em 'enxergar' objetos na superfície terrestre”, sendo que quanto menor o objeto possível de ser observado, maior será sua resolução espacial (CRÓstA, 1993); a maneira mais comum de ser determinada é pelo campo instantâneo de visada (IFOV) que define a área do terreno imageada a uma dada altitude num dado instante (pixel), um conceito teórico baseado nas propriedades geométricas do sistema sensor;

b) Resolução espectral: definida pelo número de bandas espectrais de acordo com sua largura do intervalo de comprimento de onda no EEM; quanto menor a largura do intervalo, maior será a resolução espectral do sensor;

c) Resolução radiométrica: definida pelo número de níveis digitais que representam os níveis de cinza de um pixel; "quanto maior o número de níveis, maior é a resolução radiométrica” (CRósTA, 1993).

Em sistemas sensores, também é utilizada uma outra resolução, a temporal, determinada pela freqüência com que o sensor volta a imagear a mesma cena (medida em dias ou horas).

As atividades antrópicas no semi-árido se desenvolvem, essencialmente, através de manejos não sustentáveis, ocasionando diversas modificações nos alvos naturais sobre a superfície terrestre. Diversas pesquisas têm demonstrado o potencial do PDI na detecção de áreas degradas, a partir do estudo do comportamento espectral destes alvos, "delimitando os fenômenos que caracterizam a geodinâmica de uma região do semi-árido, através de texturas, matizes e relações horizontais entre os elementos das imagens orbitais" (MALDONADO, 2001).

Uma técnica de interferometria que combina imagens de radar e ópticas, por exemplo, aumenta o sinergismo da extração de informações. Em estudos geomorfológicos, noutro exemplo, a análise das curvas de nível em planícies aluviais sobrepostas a combinações multiespectrais evidencia as áreas de erosão ou de acumulação de material do solo. Carvalho (2001), ao 
fazer uma abordagem multiescala para o monitoramento do processo de desertificação no semi-árido brasileiro, diz que a escolha metodológica de investigação do problema, associada à escolha dos indicadores, varia em função das escalas temporais e espaciais.

Assim, "as informações obtidas por sistemas sensores nos diferentes níveis de observação são complementares e integradas, parte de uma mesma realidade”. Modificações no albedo, índices de vegetação e de brilho, mudanças na forma de uso e manejo da terra, observação das condições biológicas, físicas e químicas da água, além de variações nas paisagens naturais e radiação solar, dentre outros, são exemplos de aplicações em PDI voltadas ao estudo de áreas degradadas em estado de desertificação.

Uma combinação das bandas espectrais 5, 4 e 3 do sensor LandSAT 5 TM, permitiu a COSTA et all (2001) uma interpretação das áreas de redução de biomassa na caatinga, baseada nas diferentes respostas espectrais dos alvos sensoriados perceptíveis nas imagens. Ao cruzar com mapas de solos e pesquisas de campo, os autores identificaram o estado de conservação dos recursos naturais do município de Caridade/CE, destacando as áreas degradadas "por uso não conservacionista destes solos, associados a suas próprias limitações, como a alta suscetibilidade à erosão, além do excesso de sódio, o qual limita o desenvolvimento de determinadas espécies".

Portanto, as ações do homem sobre a paisagem e sobre os recursos naturais podem ser monitoradas a partir das técnicas disponíveis no PDI, identificando os diversos graus de degradação do meio ambiente e permitindo uma quantificação das diversas áreas atingidas pelo problema.

\section{O comportamento espectral dos alvos naturais da caatinga}

O conhecimento sobre o comportamento espectral dos alvos sobre a superfície terrestre é fundamental para a extração de informações a partir de dados de Sensoriamento Remoto, assim como os fatores que interferem neste comportamento (Novo, 1989). Uma combinação de bandas espectrais que melhor discrimine um determinado alvo, por exemplo, requer conhecer o comportamento espectral deste alvo de interesse ou, então, corre-se o risco de desprezar faixas espectrais de grande importância para sua identificação.

Dentre os principais fatores que interferem nas medidas do comportamento espectral dos alvos, destacam-se: 
a) Método de aquisição: laboratório, campo ou plataforma elevada (helicóptero, avião ou satélite), utilizando-se um espectrorradiômetro para a coleta dos dados (assinatura espectral);

b) Geometria de aquisição dos dados: são parâmetros (Quadro 4) que interferem na geometria de iluminação da cena (Figura 8);

c) Parâmetros atmosféricos: umidade atmosférica, presença de aerossóis, turbulência, dentre outros;

d) Parâmetros relativos ao alvo: objetos adjacentes ao alvo de interesse podem interferir nas medidas de reflectância deste, pois uma energia diferente espalhada pela vizinhança do alvo pode mascarar sua resposta.

Figura 8: Variáveis da geometria de aquisição de dados que afetam as medidas de reflectância.

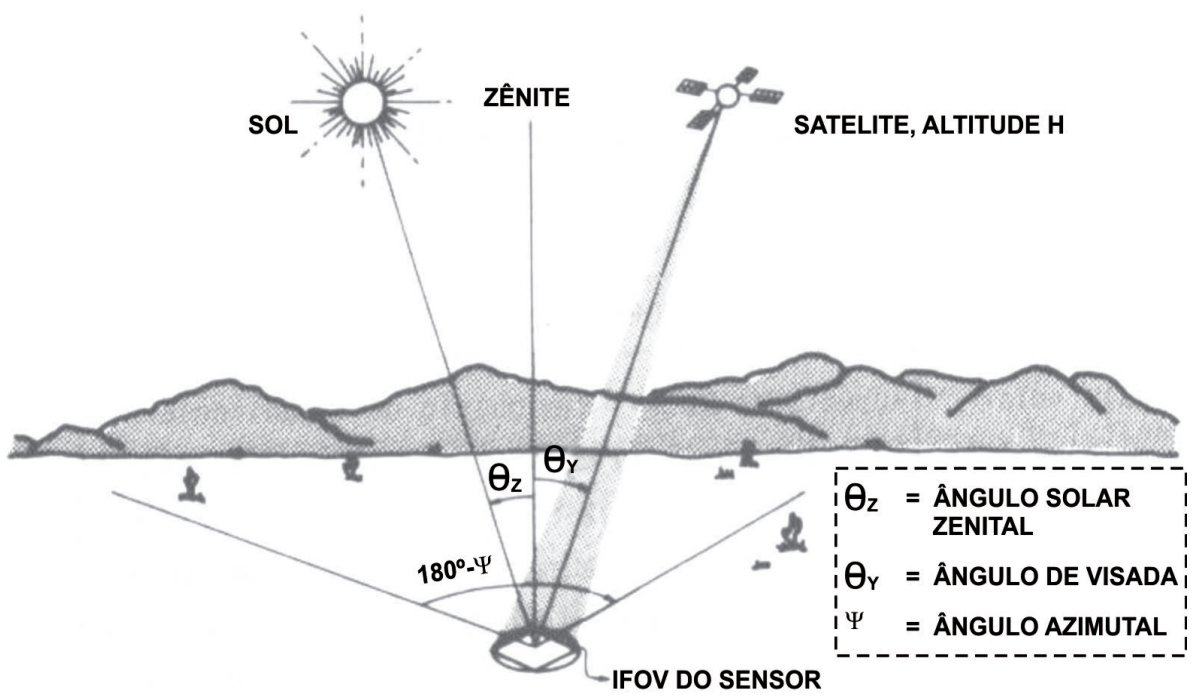

Fonte: Novo (1989).

Assim, vegetação, solos, rochas e minerais, água e superfícies construídas são alguns dos principais componentes da superfície terrestre objeto de estudo em Sensoriamento Remoto. Como dito, o conhecimento do comportamento espectral dos alvos de interesse e as interferências observadas no processo são essenciais para uma correta utilização dos dados sensoriados, objetivando fornecer extensas e precisas informações para todas as áreas das geociências, particularmente para o monitoramento ambiental. 
Neste contexto, segundo Maldonado (2001), uma das ferramentas mais importantes para o monitoramento das mudanças de cobertura e uso do solo é oriunda das imagens satelitais, sendo que "no caso de regiões semiáridas, as condições climática, edáfica e de degradação da paisagem têm importante influência na resposta espectro-textual da cobertura e uso do solo, quando observados em dados sensoriados”. Uma das técnicas mais apuradas refere-se à Análise por Componentes Principais, pois permite avaliar o grau de modificação provocada pela ação do homem na paisagem de domínio da Caatinga.

Quadro 4: Efeito das variáveis da geometria de aquisição de dados de Sensoriamento Remoto sobre as medidas de reflectância

\begin{tabular}{|l|l|}
\hline \multicolumn{1}{|c|}{ Variável } & \multicolumn{1}{c|}{ Efeito sobre as medidas de reflectância } \\
\hline Ângulo solar Zenital $(\phi z)$ & $\begin{array}{l}\text { Aumento do } \phi \mathrm{z} \text { - Diminuição da irradiância solar na superfície do alvo } \\
- \text { diminuição da porcentagem de energia refletida pela superfície. } \\
\text { Aumento do } \phi \mathrm{z} \text { - Aumento de percentagem de incidência de radiação } \\
\text { difusa sobre a superfície do alvo - aumento da componente de radiação } \\
\text { difusa sobre o alvo. }\end{array}$ \\
\hline Ângulo de visada ( $\phi \mathrm{v})$ & $\begin{array}{l}\text { Aumento de } \phi \mathrm{v} \text { - Aumento do componente de radiância da atmosfera } \\
\text { na energia refletida pela superfície - Redução do contraste entre os } \\
\text { alvos - Aumento da influência da anisotropia }{ }^{1} \text { da reflectância sobre as } \\
\text { medidas radiométricas. }\end{array}$ \\
\hline $\begin{array}{l}\text { Ângulo Azimutal do Sol e } \\
\text { do sensor }\end{array}$ & $\begin{array}{l}\text { Altera a distribuição de energia na superfície do alvo no caso de culturas } \\
\text { plantadas em linhas, no caso de lineamentos geológicos. }\end{array}$ \\
\hline Ângulo Azimutal relativo & $\begin{array}{l}\text { A variação de } \Psi \text { altera a porcentagem de energia registrada pelo sensor } \\
\text { em cada comprimento de onda. } \\
\text { Quando } \Psi=00^{\circ} \text { - maior porcentagem de energia refletida em todos os } \\
\text { comprimentos de onda, se z }=20^{\circ} \text {; } \theta \mathrm{v}=5^{\circ} \text {. }\end{array}$ \\
\hline Altitude do sensor & $\begin{array}{l}\text { Aumento de } \mathrm{H} \text { - aumento da interferência da radiância da atmosfera na } \\
\text { medida de reflectância do alvo. }\end{array}$ \\
\hline
\end{tabular}

Fonte: Novo (1989).

O mapeamento de coberturas vegetais com base em suas características fisionômicas, ecológicas e florísticas ganhou impulso considerável com o advento do sensoriamento remoto, segundo Ponzoni (2001). O autor afirma que "experimentos têm sido conduzidos em todo o mundo, buscando caracterizar o comportamento espectral das partes das plantas (...) com o objetivo de atender às necessidades específicas” de pesquisa e aplicações comerciais, propiciando o mapeamento de extensas áreas da superfície terrestre, o monitoramento, a fiscalização e o controle da exploração dos recursos naturais. 
Estudos recentes demonstram que a alteração do equilíbrio hídrico das plantas pode ser observada principalmente na região do infravermelho próximo, sendo que, no caso do sensor LandSAT 5 TM, esta característica situa-se na banda espectral 5. Observando a aparência da vegetação em imagens orbitais, verifica-se que "um dossel vegetal tem valores de reflectância relativamente baixos na região do visível, devido à ação dos pigmentos fotossintetizantes que absorvem a radiação eletromagnética para a realização da fotossíntese”. Porém, "na região do infravermelho próximo, esses valores apresentam-se elevados, por causa do espalhamento interno sofrido pela radiação eletromagnética em função da disposição da estrutura morfológica da folha, aliado, ainda, ao espalhamento múltiplo entre as diferentes camadas de folhas”. Isto tem fundamental importância da análise e processamento dos índices de vegetação da caatinga para os estudos de desertificação no semi-árido nordestino, ao eleger de forma sistemática as bandas espectrais mais adequadas à extração de informações sobre a cobertura vegetal na área em estudo, compreendendo sua morfogênese.

Também estudando o semi-árido brasileiro, Kazmierczak (1996) afirma que "dentro do domínio de aplicações de dados de sensoriamento remoto, verifica-se uma grande falta de informações sobre a Formação da Caatinga: a extensão e o pouco conhecimento existente bastariam para determinar esta região como um dos mais promissores campos de aplicação das tecnologias de sensoriamento remoto, para prover informações sobre os seus recursos". Parte do problema verificado no estudo da desertificação no passado tem sido a tendência de tratar de modo independente os diferentes aspectos a ela relacionados e que estão intrinsecamente relacionados e que levam à degradação ambiental, tanto em áreas já ocupadas, como em áreas naturais.

O autor demonstra em artigo uma metodologia para detecção de índices normalizados de vegetação da Caatinga, como um fator determinante na detecção de áreas desertificadas, a partir de séries temporais do satélite norte-americano AVHRR/NOAA e do cruzamento com dados pluviométricos de estações no semi-árido brasileiro, analisando os dados e verificando padrões de comportamento espectral dos alvos. Utilizando o NDVI, Kazmierczak (1996) observou que "quanto maior o índice de vegetação, mais densa é a fitomassa verde", pois à medida que aumenta a vegetação, aumenta também a reflexão na banda do infra-vermelho próximo, ao passo que diminui a reflexão na banda do vermelho, fazendo com que a razão entre elas seja potencializada, realçando a vegetação. 
Utilizando séries temporais, também foi constatada a componente sazonal na produção de fitomassa, em função das estações climáticas, revelando um decréscimo dos valores de NDVI à medida que avança o déficit hídrico no período das secas. Uma conclusão importante deste estudo é que "as condições secas tendem a ser mais favoráveis a discriminação de pequenas diferenças entre os diversos tipos de caatinga”, pois a época chuvosa uniformiza as respostas espectrais das diferentes tipologias existentes na região semi-árida.

Por outro lado, Costa et all (2001) também observam que a dinâmica do uso da terra na Caatinga, ao utilizar de modo não sustentável os recursos madeireiros, vem provocando perda da diversidade florística e contínua degradação do solo, estando intimamente relacionados a presença de processos desertificatórios na região de Seridó, no Rio Grande do Norte. Os autores, então, propõem um método para o mapeamento da fitomassa da Caatinga, baseando-se no índice de Área de Planta e no NDVI, obtidos com dados do sensor LandSAT 7 ETM+, o mesmo a ser utilizado no âmbito desta pesquisa. Técnicas de processamento digital de bandas espectrais nas regiões do infravermelho próximo (sensores TM3 e TM4) permitem uma melhor resposta espectral para a identificação da cobertura vegetal na área imageada.

Carvalho (2001), ao fazer uma abordagem multiescala para o monitoramento de indicadores do processo de desertificação, observou que, no nível de percepção regional, as medidas devem ser feitas em escalas temporais da ordem de grandeza de décadas a anos, onde "a ação do homem e dos animais se faz sentir de forma bastante expressiva na paisagem natural".

Ao pesquisar os processos desertificatórios em Alagoas, Assis (2002) utilizou-se de imagens LandSAT 5 TM para detectar a ocorrência de desmatamentos e seus estados de maior ou menor degradação ambiental, chegando a conclusão que cerca de $93 \%$ da classe caatinga estava degradada no trópico semi-árido estadual, apresentando áreas de ocorrência muito grave de desertificação, com "características de terras arrasadas".

Consolida-se, portanto, a importância do conhecimento espectral dos alvos naturais da caatinga para o desenvolvimento de uma metodologia de pesquisa em Sensoriamento Remoto que de fato possa responder adequada e cientificamente às questões pertinentes ao patrimônio ambiental na área em estudo, quantificando, identificando e localizando as ações antrópicas que estejam desestruturando o frágil equilíbrio do meio ambiente natural da área em estudo, no caso, a Região de Xingó, destacando-se as técnicas que permitem detectar: os índices de vegetação, as modificações de uso e cobertura do solo e os estágios de degradação ambiental. 


\section{Nota}

1 Qualidade de um objeto que apresenta propriedades físicas diferentes em todas as direções; opõe-se a isotropia (AuRÉLIO, 1988).

\section{Referências}

ASSIS, J. S. Biogeografia e conservação da biodiversidade. Maceió, AL: Catavento, 2000. 199 p. . Desertificação em Alagoas (Análise Físico-Ambiental Preliminar). Maceió, AL: UFAL, 2002. Apostila.

CARVALHO, V. Abordagem multiescala para o monitoramento de indicadores do processo de desertificação. In: X SIMPÓSIO BRASILEIRO DE SENSORIAMENTO REMOTO, Foz do Iguaçu, 2001, p. 1539-1551. Anais.

COLWELL, R. N. Manual of Remote Sensing. Falls Church, Virginia: American Society of Photogrammetry, 1983.

COSTA, T.; ACCIOLY, L.; OLIVEIRA, M.; BURGOS, N.; SILVA, F. Mapeamento da Fitomassa da Caatinga do Núcleo de Desertificação do Seridó, pelo Índice de Área de Planta (IAP) e o Índice de Vegetação da Diferença Normalizada (NDVI), obtido com dados do Sensor Landsat 7 TM. In: X SIMPÓSIO BRASILEIRO DE SENSORIAMENTO REMOTO, Foz do Iguaçu, 2001, p. 1563-1573. Anais.

ERDAS, Field Guide. 5. ed. Atlanta: ERDAS Inc., 1999.

FLORENZANO, T. Imagens de satélite para estudos ambientais. São Paulo: Oficina de Textos, 2002. $97 \mathrm{p}$.

INPE. Tutorial do Spring. São José dos Campos, SP: INPE, 2001. 305 p. (Apostila).

JENSEN, J.R. Introductory Digital Image Processing: a Remote Sensing Perspective. Englewood Cliffs, New Jersey: Pretice-Hall, 1999.

KAZMIERCZAK, M. Uso de dados AVHRR/NOAA GAC para análise da sazonalidade da caatinga. Fortaleza, CE: Fundação Cearense de Meteorologia e Recursos Hídricos, 1996.

MALDONADO, F. Rotação Espectral Controlada como alternativa em Análise por Componentes Principais para detecção de mudanças em regiões do semi-árido. In: X SIMPÓSIO BRASILEIRO DE SENSORIAMENTO REMOTO, Foz do Iguaçu, 2001, p. 627-630. Anais.

MOREIRA, M. Fundamentos do sensoriamento remoto e metodologias de aplicação. 2. ed. Viçosa, MG: UFV, 2003. 307 p.

NOVO, E. Sensoriamento Remoto: princípios e aplicações. São Paulo: Edgard Blücher, 1989. $293 \mathrm{p}$.

PERAZZO, G. M; KATO, M. T.; FLORENCIO, L. Avaliação do Saneamento Ambiental em 29 Municípios na Região do Semi-Árido, Nordeste do Brasil. In: XXVIII Congresso Interamericano de Ingeniería Sanitária y Ambiental. Anais. Cancún, México, 2002. 
PONZONI, F. J. Comportamento Espectral da Vegetação. In: MENESES, P. R., NETTO, J. S. M. SENSORIAMENTO REMOTO - REFLECTÂNCIA DOS ALVOS NATURAIS. Brasília, DF: UnB; Planaltina: Embrapa Cerrados, 2001. 262p.

STAR, J.; ESTES, J. Geographic Information Systems: An Introduction. Englewood Cliffs, New Jersey: Prentice-Hall, 1990.

SUITS, G. H. Manual of Remote Sensing. Falls Church, Virginia: American Society of Photogrammetry, 1983.

ADMILSON P. PACHECO - Professor adjunto da UFPE, graduado em Física, Mestre em Sensoriamento Remoto pelo INPE e Doutor em Geofísica pela USP. Coordenador do Programa de Pós-Graduação em Ciências Geodésicas e Tecnológicas da Geoinformação pela UFPE.

NEILSON CABRAL FERREIRA FREIRE - Graduado em Geografia pela UFPB, Mestre em Ciências Geodésicas e Tecnológicas da Geoinformação pela UFPE. Doutorando do curso de geografia da UFPE.

UTAIGUARA DA NÓBREGA BORGES - Mestrando em Ciênicas Geodésicas e Tecnológicas da Geoinformação pela UFPE. 